\title{
Marginalidad de la democracia. Comentario a Alfonso Ruiz Miguel, Cuestiones de principios: entre política y Derecho*
}

\author{
(2020) Centro de Estudios \\ Políticos y Constitucionales \\ Madrid, 615 pp.
}

\author{
Mauro Barberis \\ Università di Trieste \\ ORCID ID 0000-0002-1913-0863 \\ barberis@units.it
}

Cita recomendada:

Barberis, M. (2021). Marginalidad de la democracia. Comentario a Alfonso Ruiz Miguel, Cuestiones de principios: entre política y Derecho. Eunomía. Revista en Cultura de la Legalidad, 20, pp. 433-438. doi: https://doi.org/10.20318/eunomia.2021.6087

Recibido / received: 01/02/2021

1. Cuestiones de principios es un libro elaborado, ambicioso y exigente que reclama mucha atención incluso para un lector no extraño a sus temas como yo mismo. Al tiempo, es l'oeuvre d'une vie ${ }^{1}$ que recoge ensayos publicados sobre diversos temas filosóficos políticos y teórico jurídicos a lo largo de treinta años: de 1989 a 2019; años en que fueron publicados los dos trabajos que examinaré principalmente. Esta perspectiva frustra la búsqueda de hilos conductores que permitan coser entre sí contribuciones que resultan heterogéneas.

Además, y sobre todo, los diferentes trabajos se ubican en un nivel de abstracción tan elevado que deja a un lector contextual como yo, solo ante los textos $y$, por decirlo de alguna forma, sin otro contexto de referencia que la historia universal de los últimos treinta años. Desde este punto de vista, el libro podría considerarse también como un ejemplo paradigmático del grado de sofisticación alcanzado por los estudios analíticos en España tras el retorno de la democracia, con la apertura de la universidad a los investigadores de la generación de Ruiz Miguel.

En breve, aceptaré el reto concentrándome sobre el texto más intrigante de la recopilación: el ensayo de 1989 sobre el ámbito de la democracia. En 1989, el texto

\footnotetext{
* Traducción de José María Sauca.

${ }^{1}$ Nota del traductor: «la obra de una vida», en francés en el original.
} 
planteaba el problema de la imposibilidad de la democracia de delimitar sus propias competencias (Laporta, 2020, p. 21) pero hoy plantea, como poco, otros problemas. En el actual Estado constitucional (e internacional), y a pesar de las pretensiones de diversos populismos, el espacio por el voto democrático parece restringirse más que ampliarse, revelándose cada vez más marginal en el sentido que se verá.

2. Publicado originalmente en Doxa, «Problemas de ámbito de la democracia» se pregunta, caso por caso, en qué ámbito personal (de quién), territorial (dónde) y material (qué, sobre qué materias) está justificado decidir por mayoría, pero fijando también tanto las reglas como los principios. El problema surge por la institución del Estado -el gobierno de una población en un determinado territorio- pero también por las instituciones infraestatales (Länder, regiones autónomas) y las supraestatales (ONU, UE, Consejo de Europa), por no hablar de las instituciones privadas o del tercer sector.

Por «democracia», Ruiz Miguel entiende oportunamente la democracia liberal: un «método de gobierno» en el que el consenso de los ciudadanos está garantizado por medio de votaciones "según la regla de la mayoría» ${ }^{2}$; es decir, indica no solo la regla de la mayoría, con todos sus límites y aporías ya señaladas por Bobbio (1981, p. 331, n. 1) sino también los derechos de libertad y los «procedimientos universales» (Bobbio, 1987) que conforman las precondiciones liberales y constitucionales de la democracia (liberal).

Ciertamente, Bobbio ha considerado la implementación de algunos derechos sociales como pre-precondiciones de las propias precondiciones liberales pero se ha ocupado, principalmente, de los aspectos formales o procedimentales de la democracia. Ruiz Miguel va más allá y en una doble dirección. Por un lado, se pregunta cuáles son las condiciones no solo formales sino también materiales de la democracia: sobre qué materias ella puede decidir con su método característico, el voto mayoritario. Por otro, se pregunta si ese método solo es válido en el nivel estatal o también en el infra-estatal y supra-estatal.

En la primera dirección, sobre el ámbito material de la democracia, Ruiz Miguel sostiene que las materias sobre las que ella puede decidir dependen de su propio principio justificativo, la autonomía: todos y cada uno tiene derecho de participar en las decisiones que le afectan. Sin embargo, él mismo constata que en un mundo cada vez más pequeño y conectado, quizá, todo parece afectar a todo, incluidas las generaciones futuras. Así, el criterio para determinar el ámbito material acaba por depender de los diferentes contextos de toda decisión democrática sin poderlos fijar a priori.

Aquí Ruiz Miguel, como señala Laporta, admite la imposibilidad del método democrático de justificar mayoritariamente la propia competencia material. Tal competencia puede estar justificada solo por una decisión de segundo nivel: una meta-decisión constitucional explícita o implícita. Además, para Ruiz Miguel, el principio justificativo de la propia democracia, la autonomía como derecho de todos a participar en las decisiones que le afectan, no es sino una meta-metadecisión de modo que la justificación, como siempre, corre el riesgo de una regresión al infinito.

Por el contrario, en la segunda dirección, esto es, sobre el ámbito territorial de la decisión democrática, el autor llega a conclusiones más claras. Respecto a la fijación de las competencias infraestatales, Ruiz Miguel siempre ha preferido la negociación desarrollada en el nivel constitucional al método democrático aplicado en

\footnotetext{
2 Nota del traductor: en español en el original.
} 
el nivel local. El referéndum convocado en 2017 sobre la independencia de Cataluña, no admitido por la Constitución española, hace aún más clara esa preferencia (Ruiz Miguel, 2020, p. 345, n. 12 y, en su totalidad, el último ensayo de la recopilación, pp. 595-604).

Respecto de la fijación de las competencias supraestatales, cuya exigencia se ha multiplicado después de 1989, Ruiz Miguel parece favorable a una extensión del método democrático que, sin embargo, no puede ciertamente consistir en atribuir un voto a cada estado, independientemente de su población. Al contrario, «también las decisiones internacionales, para ser democráticas, deberían adoptarse mediante un sistema de representación de la población, todo lo ponderado que se quiera, pero de representación de individuos a fin de cuentas» (2020, p. 351).

3. Aceptando que la vertiginosa síntesis que he formulado apenas capta, siquiera, las tesis de fondo de Ruiz Miguel, en el espacio de una nota no pretenderé discutirle una por una. Más bien, y más rápidamente aún, volveré a replantear el problema del ámbito de la democracia en el actual Estado constitucional (e internacional). Aquí, de hecho, ese ámbito se restringe al punto de que la democracia y el voto mayoritario corren el riesgo de convertirse en lo que quizás siempre han sido: un método político tanto irrenunciable como marginal, respecto del conjunto, variedad y complejidad de los problemas prácticos.

En el Estado jurisdiccional, el primero de los tres estados o fases de la modernidad (Fioravanti, 2001), la tarea de la política y del derecho era fundamentalmente la justicia que, desde la antigüedad, se ocupa principalmente de la distribución de los bienes. Sin embargo, como muestra Walzer (1983), los bienes diferentes pertenecen a esferas diferentes en las cuales son distribuidos en formas aún más variadas. Además, antes de las grandes Revoluciones occidentales, nadie reclamaba la democracia y el típico método democrático, el voto mayoritario, tenía aplicaciones esporádicas y rudimentales.

Todo cambia, aparentemente, con el paso al Estado legislativo y la dislocación de la soberanía del monarca al pueblo representado en un Parlamento también soberano, competente para legislar sobre cualquier materia. En el régimen de constituciones flexibles, en efecto, los poderes del Parlamento no están realmente limitados por las declaraciones de derechos. En la práctica, la legislación se extiende de hecho a todos los ámbitos de la vida social e, incluso en la teoría, la utilidad, sustituta positivista de la justicia, tampoco admite límites, ni siquiera de parte de los derechos individuales. Solo en el Estado constitucional (e internacional), tras la Segunda Guerra Mundial, las competencias y los límites del Parlamento son fijados expresamente por constituciones rígidas y garantizadas y también por tratados internacionales con efectos internos en los estados. Así, según Pappas (2019), solo esta puede concebirse como la auténtica democracia liberal. Sin embargo, después de los trente glorieuses années ${ }^{3}$ en los que las constituciones y los tratados aún vigentes han producido el welfare state, la democracia liberal ha sido atacada en todas sus conquistas.

El primer ataque, una reducción radical del ámbito de la democracia, ha venido del neoliberalismo a partir de los años setenta: reducción de la presión fiscal sobre los ricos, recortes del gasto social, privatizaciones, deregulation, deslocalizaciones de empresas, globalización económica y financiera (Harvey, 2005). El segundo ataque, una reacción al primero que muchas veces no hace más que proseguirlo, se llama

\footnotetext{
${ }^{3}$ Nota del traductor: «los treinta años gloriosos», en francés en el original.
} 
populismo o sovranismo ${ }^{4}$, según erosione solo los límites constitucionales o también los límites internacionales del ámbito de la democracia.

En 1989, año del ensayo de Ruiz Miguel, el ataque neoliberal era ya visible, mientras que el ataque populista parecía excluido por el triunfalismo generado tras el colapso del comunismo. Sin embargo, el problema de la delimitación del ámbito de la democracia, propuesto entonces por Ruiz Miguel, se extiende fácilmente a los problemas actuales y así se revela más actual hoy que entonces. Probemos a poner tres ejemplos de plena actualidad, uno ya aludido por el propio autor, los independentismos, los otros dos añadidos por mí: los populismos y la emergencia de la pandemia.

El referéndum catalán de 2017, antes de nada, se presta a dos lecturas: una solo constitucional; la otra también internacional. Ruiz Miguel proporciona sólo una lectura constitucional: el referéndum independentista era inconstitucional porque forzaba el ámbito de la democracia fijado por la Constitución española. Ferrer (2017) y Barberis (2017) añaden una lectura también internacional. A saber, el problema de los independentismos europeos podría ser renegociado en los Tratados europeos dentro de una Unión Europea concebida como federación de las Regiones y no de los Estados.

Los diversos populismos que explotaron en 2016 han compartido precisamente este forzamiento del ámbito de la democracia liberal. La «población», así llamada por Ruiz Miguel, se convierte en «pueblo» en los medios de comunicación y reclama decidir por mayoría, o por plebiscito, fuera de los límites constitucionales e internacionales de la democracia, sobre cualquier materia. La democracia liberal deja así el lugar a la democracia populista, iliberal y anti-pluralista: la pluralidad de las esferas de la justicia de Walzer queda expuesta al arbitrio de los líderes populistas autorizados por el pueblo para decidir sobre cualquier cosa y su contraria.

Finalmente, la pandemia es solo la última de las emergencias del siglo XXI en un orden temporal, pero muestra también la tendencia populista a forzar el ámbito de la democracia en nombre de la propia democracia. Aparentemente, para los líderes populistas incluso la gestión de la pandemia debería ser "democrática» ya que de lo contrario se caería en la «dictadura sanitaria» de los científicos y de las Big Pharma ${ }^{5}$. Sin embargo, según la Constitución italiana (art. 32 , pfo. $2^{\circ}$ ) incluso se podría decidir democráticamente, mediante la ley, la obligación de vacunarse.

Por otro lado, también en este caso, como ocurre a menudo en el propio Estado constitucional, la decisión del Parlamento acabaría por revelarse una forma de ratificación. De una forma algo más vistosa que en la política ordinaria, la institución elegida por la mayoría, el Parlamento, se limita a controlar y, normalmente, ratificar el trabajo de las instituciones contra-mayoritarias o no-mayoritarias que gestionan directamente la pandemia: los comités científicos, el gobierno central, las regiones autónomas, las administraciones centrales o regionales, las autoridades independientes...

\footnotetext{
${ }^{4}$ Nota del traductor: El término de «soberanismo» tiene -al menos en el español peninsular-, como campo semántico preferente el referido a los movimientos vinculados a los nacionalismos periféricos. En el contexto del populismo, en ocasiones, se hace referencia al término «patriotismo» pero su vaguedad es aún mayor. Quizá el término de uso más profuso para referirse a esta dimensión de los movimientos populistas es el de «nacional-populismo» o «populismo nacionalista». Ante estas indeterminaciones se ha preferido respetar el término original en italiano.

${ }^{5}$ Nota del traductor: «las grandes farmacéuticas».
} 
Recapitulando, aún más rápidamente, Ruiz Miguel admite que el problema del ámbito de la democracia y de su técnica de decisión característica, el voto mayoritario, es irresoluble con base en su principio justificativo, la autonomía, y debe situarse en los niveles lógicamente superiores, no legislativos sino constitucionales o internacionales. Coincido con él, pero el ataque populista al Estado constitucional nos obliga a recordar límites que incluso van más allá: límites a la propia esfera de la política, lo que, en el Occidente actual, es a la propia democracia.

Como han sostenido, de maneras diferentes, autores politeístas, pluralistas y liberales como Max Weber, Michael Walzer e Isaiah Berlin, la política solo es una esfera de la práctica, junto al Derecho, la moral, la economía. Sin embargo, a la esfera de la práctica se añaden, seguidamente, las esferas vitales ulteriores: ciencia, arte, religión (Barberis, 2006, 2008). La democracia, el voto mayoritario, sólo tienen sentido dentro de la esfera de la política y no fuera de ella. Esto es lo que entiendo cuando, usando una expresión de Hardin [1999 (1997)], hablo de la marginalidad de la democracia. Repito, la democracia es irrenunciable, pero está sujeta a un doble límite: por un lado, el límite de la constitución y de los tratados internacionales y, por otro, los límites de la propia política.

\section{Bibliografía}

Barberis, M. [2008 (2006)]. Etica para juristas, Madrid: Trotta.

Barberis, M. (2017). L'incredibile e triste storia della candida Catalogna e della sua Spagna snaturata. En Governare la paura, 10 novembre, pp. 9-18. Disponible en: https://www.google.com/search?client=firefox-be\&q=Barberis $\% 2 C+L \% 27$ incredibile+e+triste+storia+Governare+la+paura [consultado el 5 de marzo de 2021].

Bobbio, N. (1981). La regola di maggioranza: limiti e aporie. En Id., Teoria generale della politica (pp. 383-410), a cura di M. Bovero. Torino: Einaudi. Edición española: La regla de la mayoría: límites y aporías. En Id. (2003). Teoría general de la política (pp. 462-489), trad. Antonio de Cabo y Gerardo Pisarello. Madrid: Trotta.

Bobbio, N. (1986). Democrazia ed Europa. En Id., Teoria generale della politica (pp. 370-383), a cura di M. Bovero. Torino: Einaudi. Edición española: De la ideología democrática a los procedimientos universales. En Id. (2003). Teoría general de la política (pp. 449-461), trad. Antonio de Cabo y Gerardo Pisarello. Madrid: Trotta.

Ferrer, J. (2017). Sobre Catalunya y España. Frente a los nacionalismos, pluralidad.

En Agenda Pública. El Periódico, 10 octubre. Disponible en: https://agendapublica.elperiodico.com/catalunya-espana-frente-losnacionalismos-pluralidad/ [consultado el 5 de marzo de 2021].

Fioravanti, M. (2002). Stato e costituzione. En Id. (a cura di), Lo Stato moderno in Europa. Istituzioni e diritto (pp. 3-36). Roma-Bari: Laterza. Edición española: En Id. (2004). Estado y constitución. En Id. (ed.), El Estado Moderno en Europa. Instituciones y Derecho (pp. 13-43), trad. M. Martínez Neira. Madrid: Trotta.

Hardin, R. [1999 (1997)]. Democracy on the Margin. En Id., Liberalism, Constitutionalism, and Democracy (pp. 276-310). Oxford: Oxford University Press.

Harvey, D. (2005). Brief History of Neoliberalism. Oxford: Oxford University Press. Edición española: Id. (2007). Breve historia del neoliberalismo, trad. Ana Varela Mateos. Madrid: Akal.

Laporta, F. (2020). Prólogo. En A. Ruiz Miguel, Cuestiones de principios: entre política y Derecho (pp. 17-28). Madrid: Centro de Estudios Políticos y Constitucionales. 
Ruiz Miguel, A. (2020). Cuestiones de principios: entre política y Derecho. Madrid: Centro de Estudios Políticos y Constitucionales.

Pappas, T.S. (2019). Populism and Liberal Democracy. A Comparative and Theoretical Analysis. Oxford: Oxford University Press.

Walzer, M. (1983). Spheres of Justice. New York: Basic Books. Edición española: Id. (1987). Las esferas de la justicia. Una defensa del pluralismo y la igualdad, trad. H. Rubio. México: Fondo de Cultura Económica. 